\title{
Sustained Self-Regulation of Energy Intake: Initial Hunger Improves Insulin Sensitivity
}

\author{
Mario Ciampolini, ${ }^{1}$ David Lovell-Smith, ${ }^{2}$ Riccardo Bianchi, ${ }^{3}$ \\ Boudewijn de Pont, ${ }^{4}$ Massimiliano Sifone, ${ }^{5}$ Martine van Weeren, ${ }^{4}$ \\ Willem de Hahn, ${ }^{4}$ Lorenzo Borselli, ${ }^{1}$ and Angelo Pietrobelli6 \\ ${ }^{1}$ Unit of Preventive Gastroenterology, Department of Paediatrics, Università di Firenze, 50132 Florence, Italy \\ ${ }^{2}$ Department of General Practice and Primary Health Care, University of Auckland, Auckland, New Zealand \\ ${ }^{3}$ Department of Physiology and Pharmacology, Robert F. Furchgott Center for Neural and Behavioral Sciences, \\ State University of New York Downstate Medical Center, Brooklyn, NY, USA \\ ${ }^{4}$ AMC, 1100 DD Amsterdam, The Netherlands \\ ${ }^{5}$ Department of Statistics, Università di Firenze, Florence, Italy \\ ${ }^{6}$ Paediatric Unit, Università di Verona, Verona, Italy
}

Correspondence should be addressed to Mario Ciampolini, mlciampolini@fastwebnet.it

Received 4 January 2010; Revised 28 April 2010; Accepted 10 May 2010

Academic Editor: Peter Clifton

Copyright ( 2010 Mario Ciampolini et al. This is an open access article distributed under the Creative Commons Attribution License, which permits unrestricted use, distribution, and reproduction in any medium, provided the original work is properly cited.

\begin{abstract}
Background. Excessive energy intake has been implicated in diabetes, hypertension, coronary artery disease, and obesity. Dietary restraint has been unsuccessful as a method for the self-regulation of eating. Recognition of initial hunger (IH) is easily learned, can be validated by associated blood glucose (BG) concentration, and may improve insulin sensitivity. Objective. To investigate whether the initial hunger meal pattern (IHMP) is associated with improved insulin sensitivity over a 5-month period. Methods. Subjects were trained to recognize and validate sensations of $\mathrm{IH}$, then adjust food intake so that initial hunger was present pre-meal at each meal time (IHMP). The purpose was to provide meal-by-meal subjective feedback for self-regulation of food intake. In a randomised trial, we measured blood glucose and calculated insulin sensitivity in 89 trained adults and 31 not-trained controls, before training in the IHMP and 5 months after training. Results. In trained subjects, significant decreases were found in insulin sensitivity index, insulin and BG peaks, glycated haemoglobin, mean pre-meal BG, standard deviation of diary BG (BG as recorded by subjects' 7-day diary), energy intake, BMI, and body weight when compared to control subjects. Conclusion. The IHMP improved insulin sensitivity and other cardiovascular risk factors over a 5-month period.
\end{abstract}

\section{Introduction}

In industrialised countries, most people regulate their energy expenditure poorly. Individual energy expenditure may differ up to 20 -fold between resting conditions and high physical activity, but such differences have until now been weakly correlated to energy intake at subsequent meals [1]. Frequent episodes of positive energy balance can lead to insulin resistance, overweight, obesity, diabetes, and heart disease $[1,2]$. Dietary regimes that attempt to restrain eating have been only marginally successful $[3,4]$ and the feasibility of self-regulation of energy intake regimes has been questioned
[5]. A key reason for this lack of success may be that most dietary methods rely on weekly or monthly measurements of weight. These measurements provide no immediate feedback to dieters, who usually ingest food at least three times daily.

The body's own physiological signaling system is hunger. Blood glucose concentration (BG) is a reliable index of energy availability to body cells [6-8]. It seems reasonable to assume that BG slowly declines in the absence of food intake during the day until hunger emerges to trigger eating behaviour $[9,10]$. Previous studies suggested that waiting for hunger before eating is associated with a significant decrease in energy intake [11-15]. 
Subjects can be trained to predict when BG is low by attending to their subjective experience of hunger [16]. Thus low blood glucose (LBG) can be regarded as a biochemical marker for hunger. The first intimations of hunger we term Initial Hunger (IH), to differentiate it from the uncomfortable symptoms that occur when hunger is prolonged. IH is not a reflex conditioned by external events such as time or social circumstances [17]. For example, IH is not conditioned by meal times since it arises unexpectedly (outside meal times) if energy content of the previous meal was not planned to cover the intermeal interval [16]. The Initial Hunger Meal Pattern (IHMP) is a pattern of eating such that $\mathrm{IH}$ is present before most meals. We reasoned that the IHMP should predict closely regulated BG concentration with associated improvements in metabolic biomarkers.

In this study, we tested the hypothesis that the IHMP is associated with improvements in metabolic biomarkers, in particular insulin sensitivity.

\section{Methods}

\subsection{Participants}

2.1.1. Eligibility Criteria. The Paediatric Gastroenterology Unit of Florence University recruited 143 subjects to this study from 1996 to 2000. This unit diagnoses and treats celiac disease in children and adults. Aged 18 to 60 years, subjects suffered from symptoms of functional bowel disorders such as dyspepsia, abdominal pain, and diarrhoea (Figure 1) $[18,19]$. They showed no morphological, physical, or biochemical signs of organic disease $[11,18,19]$. Subjects with impaired glucose tolerance (fasting plasma-glucose $>115 \mathrm{mg} / \mathrm{dL}(6.4 \mathrm{mmol} / \mathrm{L}))$, and noninsulin dependent diabetes mellitus (NIDDM), celiac, liver, heart, brain, thyroid, and kidney diseases were excluded from this study (Figure 1). Written informed consent was obtained from all subjects. The local Hospital Ethics Committee approved the study in compliance with the Helsinki Declaration.

2.1.2. Setting. The trained group continued their regular work or recreational activities under tutorial assistance for seven weeks and maintained the IHMP for a further three months independently (Figure 1).

2.2. The Intervention. Subjects were trained in the IHMP, first by identifying $\mathrm{IH}$, which was guided by consistency in subjective sensations and the association of these sensations with BG measurement. During training, subjects measured capillary blood by portable glucometer (Glucocard Memory; Menarini Diagnostics; Florence, Italy) in the $15 \mathrm{~min}$ before a meal. Accuracy of measurements by the glucometer was validated against periodic measurements by hospital autoanalyzer. Seven-day home diaries reported BG measurements and presence or absence of IH before the three main meal times. Also recorded in the diary were energy and vegetable intake, hours in bed, and hours spent during physical and outdoor activities (weekly mean and SD). Subjects were advised that BG measurements after taking small quantities of food (even a few grams), after changes in ambient temperature, after physical activity such as walking or cycling, and when under psychological stress would be misleading since we had previously found that BG and IH do not correlate well under these conditions [16].

Subjects reported $\mathrm{IH}$ as gastric pangs, sensations of emptiness and hollowness, and mental or physical weakness [16]. IH was cultivated pre-meal by adjusting composition, portion size, or timing of food intake. After a few days of trial and error, and sometimes irregular meal times, subjects were able to arrange their food intake so that $\mathrm{IH}$ appeared before the usual three meal times per day with an average error of half-an-hour in $80 \%$ of instances [15, 16, 20-23]. Training ended after the first 7 weeks, to be resumed only at the end of the investigation. Thus, after the first 7 weeks, subjects relied upon the identified subjective sensation (IH) alone, as the signal to begin a meal. Control subjects $(N=31)$ were given the same information on food energy content and were recommended vegetable intake and physical activity per day as were the trained subjects (weeks 0-7, Figure 1).

120 subjects who completed the study were assessed for blood parameters at baseline (before training), after the first 7 weeks of training, and at the end of the investigation after a further three months (total duration of the investigation: 5 months). During the glucose tolerance test, after a 12hour overnight fast, all subjects were given a 75 g-oral glucose load. Venous blood samples were taken immediately before glucose was administered, and 30, 60, 90, 120, and $180 \mathrm{~min}$ thereafter to determine plasma glucose and serum insulin. Serum insulin was measured with the IMx insulin assay (Abbott Lab. Diagn. Div. USA) [24]. From the glucose tolerance test (GTT), we calculated the area under the curve (AUC), the index of whole-body insulin sensitivity $(10,000 /$ square root of [fasting glucose $\times$ fasting insulin] $\times$ [mean glucose $\times$ mean insulin during GTT]) [25], and the insulinogenic index of beta cell function (ratio of the increment of plasma insulin to that of plasma glucose $30 \mathrm{~min}$ after glucose loading) [26].

\subsection{Outcomes}

2.3.1. Primary Endpoint. The primary endpoint was the change in insulin sensitivity [25] from baseline at 5 months in trained subjects compared to controls.

2.3.2. Secondary Endpoints. Analyses were also performed on beta cell function [26], BG AUC, GTT measurements of $B G$ and insulin concentrations, and mean pre-meal BG and $\mathrm{HbA1c}$ values [27] as well as energy intake, BMI, body weight and arm and leg skinfold thickness.

2.4. Sample Size. Previous work in similar patients found that the insulin sensitivity index in the intervention group was greater by 3 than that in the control group, with a standard deviation (SD) of 3.0 [23]. Based on these figures, our sample size calculations suggested that we needed a minimum of 14 subjects in each comparison group to detect 


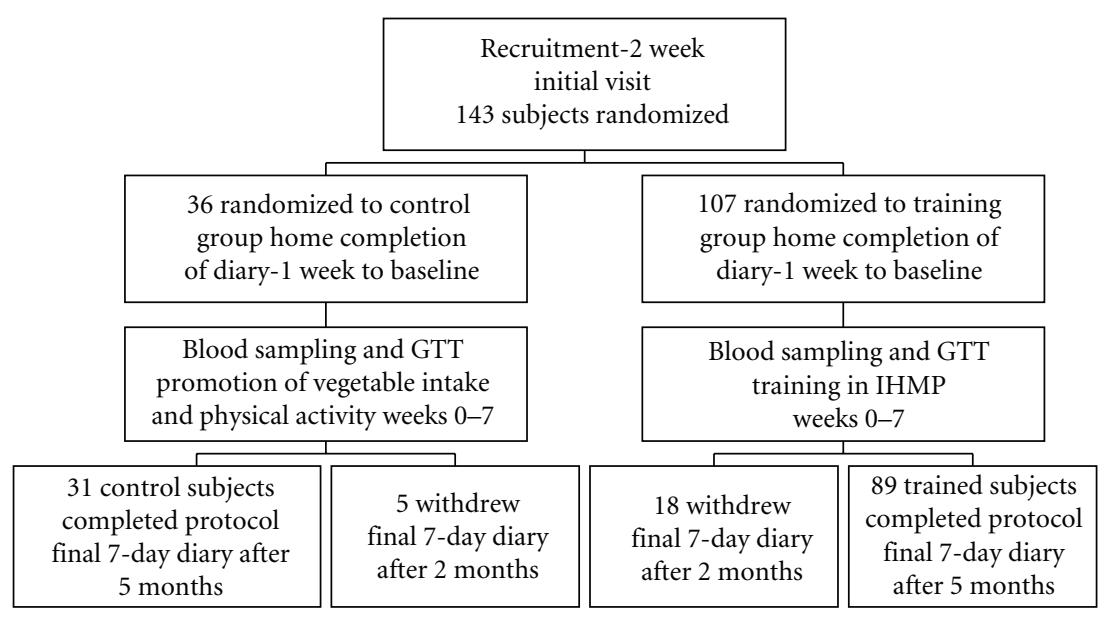

FIGURE 1: Consort flow chart and investigation design. Randomized controlled 5-month clinical investigation to study the metabolic effects of the IHMP.

a similar difference in group means, with a power of $80 \%$ and a 1 sided alpha of 0.05 .

2.5. Randomization. A list was divided into blocks of 1 to 4 places, and the blocks were randomly assigned using Armitage even and odds random numbers on a $3: 1$ ratio to either training or control groups. A dietician kept the list and subsequently assigned each recruited subject to the first empty list place. Control or training destination was revealed after the first visit (Figure 1).

2.6. Statistical Methods. Values are expressed as means \pm SD, except in Figure 2, where the Standard Error is shown. Logistic regression analysis was used to investigate the association of training with BG mean, $\mathrm{Hb} 1 \mathrm{c}$, insulin and BG AUCs, intakes and anthropometric measures (trained versus untrained control groups) for significance of multiple results [28]. The significance of difference and correlation was set at $P<.05$ in these analyses. Yates test and two-tailed Student's $t$-test on paired or unpaired samples according to data requirements were used to analyse the significance of difference and two-tailed Student's $t$-test for correlation. The significance was set at $P<.05$ for single measurements and at $P<.025$ for the GTT insulin and BG AUCs [29]. Custom-made software was used to tabulate data for statistical analyses. Microsoft Excel (Microsoft Corp., USA) and SAS 8 (SAS Institute Inc., Cary, NC, USA) were used for data presentation and for statistical analyses.

A training effect and correlations between the two body size parameters (weight and BMI), the two energybalance parameters (arm and skinfold thickness), the four metabolic indexes (mean BG and $\mathrm{HbAlc}$ values, and BG and insulin AUCs), and three intake factors (energy, fruit, and vegetable) were longitudinally investigated (i.e., on post minus predifferences) by simple, linear correlation and regression analyses in all of the 120 subjects completing the study (Figure 1). Results were validated by chi square testcollinearity diagnostics-residual analysis.

\section{Results}

Figure 1 shows the flow chart of participants through each phase of the study. Data were eventually collected from 120 subjects who completed the study (60 females and 60 males, 89 trained subjects and 31 control subjects).

\subsection{Losses and Exclusions}

3.1.1. Protocol Deviations. In this study the protocol was to follow the IHMP. We do not have data on the extent to which IH was present pre-meal for each meal, that is, we do not know how closely each subject adhered to the IHMP. Achieving the IHMP appeared to be difficult for 12 subjects who had high pretraining mean BG concentrations (e.g., around $100 \mathrm{mg} / \mathrm{dL}$ ) or participated in heavy manual labour, especially in cold conditions. Although some subjects may not have been faithful to the IHMP for all meals, we have included all those who completed the study in the final analysis, since it was our intention to treat them $[30,31]$.

3.1.2. Dropouts. Twenty-three subjects (18 trained and 5 control) did not complete the study (dropouts). All were contacted by telephone. Their given reasons were that they "required no further training" or had "busy schedules." To ascertain whether these biases could have affected the generalisability of the study's conclusions, we performed a sensitivity analysis using baseline and 7-week data from all 23 dropouts. The 18 trained dropouts significantly decreased mean BG (from $83.3 \pm 5.9 \mathrm{mg} / \mathrm{dL}$ to $78.9 \pm 5.4 \mathrm{mg} / \mathrm{dL} ; P=$ .005 ), energy intake (from $1651 \pm 451$ to $1124 \pm 401 ; P=$ .0001 ), BMI (from $23.7 \pm 3.4$ to $22.9 \pm 3.2 ; P=.04$ ), and arm skinfold thickness (from $20.5 \pm 8.5$ to $18.5 \pm 8.8 ; P=.03$ ). The 5 control dropout subjects showed no change in these assessments.

3.2. Baseline Demographics. Since no significant gender difference in baseline mean BG concentrations was observed 


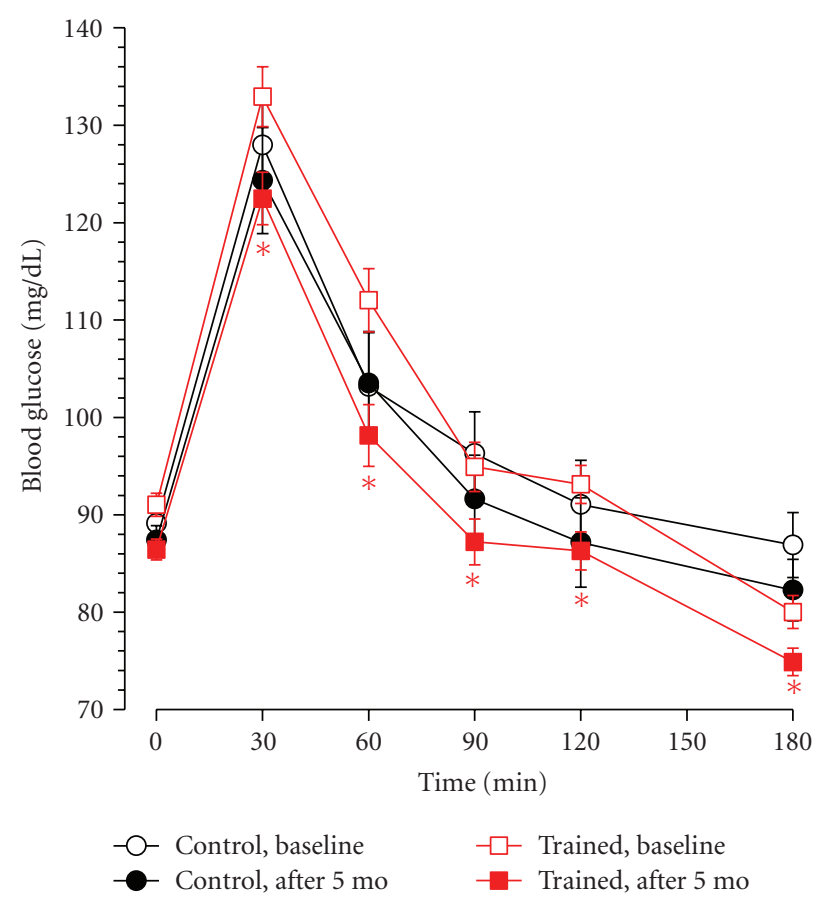

(a)

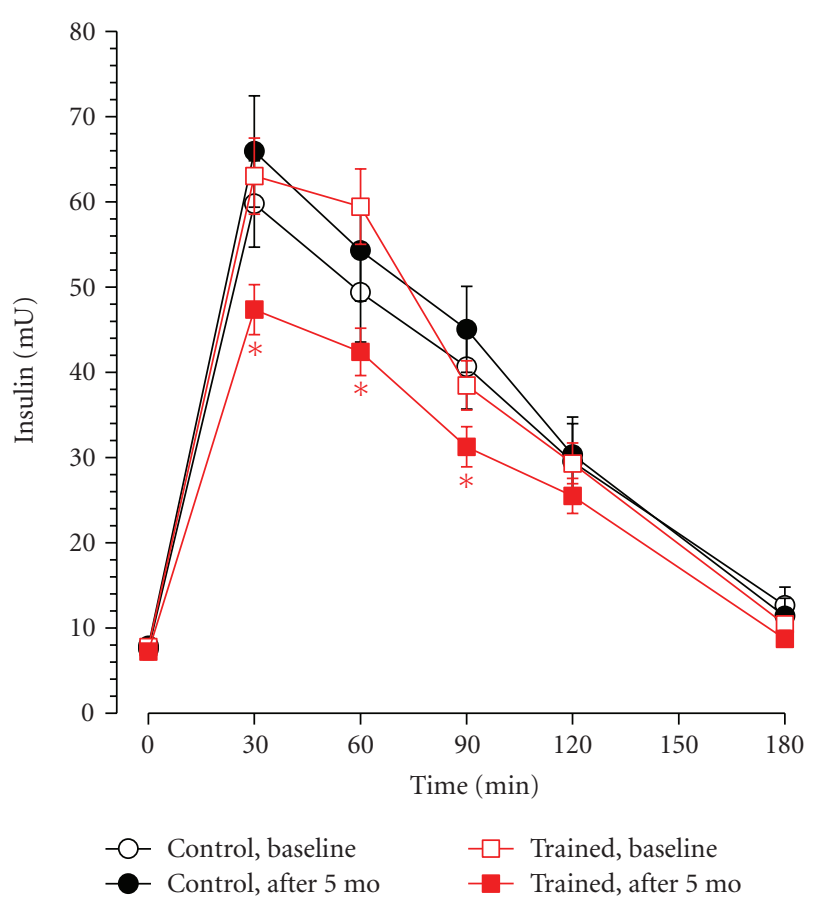

(b)

FIGURE 2: Blood glucose and plasma insulin concentrations during GTT in control and trained subjects at the beginning and at the end of the study. Blood glucose (a) and insulin (b) mean levels in control (black circles) and trained (red squares) subjects at baseline (open symbols) and after 5 months (closed symbols). Vertical bars are standard errors. Asterisks indicate significant decrease of blood glucose (a) and insulin (b) in the trained subjects after training compared to their respective baseline values $(P<.01)$. In contrast, no decrease between baseline values and those at the end of the study was observed in control subjects. The insulin decrease in trained subjects at 60 and 90 min also differed significantly from the control group $(P<.01$ and $<.05$, resp. $)$.

in the control group (females: $82.3 \pm 8.0 \mathrm{mg} / \mathrm{dL} ; N=14$; and males: $87.5 \pm 7.6 \mathrm{mg} / \mathrm{dL} ; N=17$; Student's $t$-test for unpaired data: $P=.075$ ) and in the training group (females: $84.3 \pm 8.7 \mathrm{mg} / \mathrm{dL} ; N=46$; and males: $87.5 \pm 10.6 \mathrm{mg} / \mathrm{dL}$; $N=43 ; P=.115)$, the measurements from both genders were pooled in each group (Figure 1). Baseline BG means of the control subjects $(85.2 \pm 8.1 \mathrm{mg} / \mathrm{dL} ; N=31)$ did not differ from those of the training subjects $(85.9 \pm 9.7 \mathrm{mg} / \mathrm{dL} ; N=89$; $P=.733$ ).

Baseline values of mean age, school education years, body weight, BMI, arm and leg skinfold thickness, and blood values did not significantly differ between control and trained groups (Tables 1 and 2).

3.3. Outcomes. Significant decreases among trained subjects compared to controls were found in insulin sensitivity index, insulin and BG peaks, insulin at 60 minutes and 90 minutes during GTT, glycated haemoglobin, mean pre-meal BG, BG diary standard deviation (SD), energy intake, BMI, body weight, arm and leg skinfold thickness.

Index of beta cell function changed from $1.0 \pm 0.8$ to $1.1 \pm$ 1.1 in trained subjects and from $1.0 \pm 1.0$ to $0.7 \pm 0.6$ in control subjects. These changes were not significant. Insulin and BG AUCs in the trained group significantly decreased in the pre/postcomparison but the decreases were not significantly different from those of the control subjects.
A significant decrease of preprandial BG mean values achieved during training was maintained three months after the training period ceased (baseline: $85.6 \pm 9.5 \mathrm{mg} / \mathrm{dL}$; after 5 months: $79.4 \pm 6.5 \mathrm{mg} / \mathrm{dL} ; N=89$; Student's $t$-test for paired data: $P<.0001$ ) (Table 2$)$. In contrast, mean preprandial BG in control subjects did not change from baseline (baseline: $85.2 \pm 8.1 \mathrm{mg} / \mathrm{dL}$; after 5 months: $85.3 \pm 7.6 \mathrm{mg} / \mathrm{dL} ; N=31$; $P=.935)$ and the longitudinal difference from the trained group was significant $(P<.001$; Table 2$)$.

3.3.1. Ancillary Analyses. The absolute pre/post change (increase or decrease) in 31 control subjects was $6.0 \pm$ $4.6 \mathrm{mg} / \mathrm{dL}(13.2 \% \pm 10.1 \%$ of the baseline range in mean BG in the 120 investigated subjects: $64.5 \mathrm{mg} / \mathrm{dL}$ to $109.9 \mathrm{mg} / \mathrm{dL}$ ). Factors that most characterized the differences between the trained group and the control group were investigated in all 120 subjects together by a logistic regression analysis. Energy intake $(P=.004)$ and HbAlc $(P=.0001)$ were significantly and negatively associated with the training. Further effects associated with training were investigated by stepwise regression analysis. The training was significantly and negatively associated with BMI $(P=.001)$ and with arm and leg skinfold thickness (balance during the 5 months of investigation; $P=.005$ and $P=.015$, resp.). Decrease in BMI by training was significantly associated with decreases in energy intake $(P=.001)$ and insulin 
TABLE 1: Group composition and effects of training on anthropometry.

\begin{tabular}{|c|c|c|c|c|}
\hline & \multicolumn{2}{|c|}{ Control } & \multicolumn{2}{|c|}{ Trained } \\
\hline & Baseline & After 5 mo. & Baseline & After 5 mo. \\
\hline Number of subjects and Gender & $14 \mathrm{~F}+17 \mathrm{M}$ & & $46 \mathrm{~F}+43 \mathrm{M}$ & \\
\hline Schooling (years) ${ }^{1}$ & $10.6 \pm 3.2$ & & $12.0 \pm 2.7$ & \\
\hline Age $(\text { years })^{1}$ & $29.6 \pm 8.2$ & & $32.6 \pm 8.5$ & \\
\hline BMI & $22.2 \pm 4.5$ & $22.5 \pm 3.7$ & $23.0 \pm 3.8$ & $22.1 \pm 3.1^{* * * a * * * b}$ \\
\hline Weight $(\mathrm{Kg})$ & $59.6 \pm 9.5$ & $60.9 \pm 8.8$ & $64.1 \pm 12.7$ & $62.0 \pm 11.3^{* * * a \mathrm{a} * * * \mathrm{~b}}$ \\
\hline Arm skinfold thickness (mm) & $15.2 \pm 9.8$ & $14.6 \pm 7.7$ & $16.0 \pm 8.0$ & $13.0 \pm 6.1^{* * a * * * b}$ \\
\hline Leg skinfold thickness (mm) & $20.6 \pm 12.3$ & $19.8 \pm 11.0$ & $21.6 \pm 11.1$ & $17.4 \pm 8.5^{* * \mathrm{a} * * * \mathrm{~b}}$ \\
\hline
\end{tabular}

Values are expressed as means $\pm \mathrm{SD} .{ }^{1}$ Values at the beginning of the study. Asterisks indicate significance (Student's $t$-test: ${ }^{*} P<.05 ;{ }^{* *} P<.01 ;{ }^{* * *} P<.001$ ) of longitudinal difference versus respective control group (a), or versus baseline values of the same group (b).

TABLE 2: Effects of training on metabolic and intake parameters.

\begin{tabular}{|c|c|c|c|c|}
\hline & \multicolumn{2}{|c|}{ Control } & \multicolumn{2}{|c|}{ Trained } \\
\hline & Baseline & After 5 mo. & Baseline & After 5 mo. \\
\hline Mean pre-meal BG (mg/dL) & $85.2 \pm 8.1$ & $85.3 \pm 7.6$ & $85.6 \pm 9.5$ & $79.4 \pm 6.5^{* * * a * * * b}$ \\
\hline BG diary SD $(\mathrm{mg} / \mathrm{dL})^{1}$ & $8.4 \pm 3.0$ & $9.1 \pm 3.2$ & $8.4 \pm 4.4$ & $6.1 \pm 2.4^{* * * a * * * b}$ \\
\hline Glycated $\mathrm{Hb}(\%)$ & $4.55 \pm 0.37$ & $4.71 \pm 0.40$ & $4.71 \pm 0.4 .2$ & $4.50 \pm 0.43^{* * * a} * * * b$ \\
\hline Insulin $\mathrm{AUC}^{2}\left(\mathrm{mU} \mathrm{L}^{-1} 3 \mathrm{~h}^{-1}\right)$ & $211 \pm 91$ & $225 \pm 111$ & $220 \pm 127$ & $171 \pm 89^{* * * \mathrm{~b}}$ \\
\hline Insulin peak $\left(\mathrm{mU} \mathrm{L}^{-1}\right)$ & $71 \pm 32$ & $74 \pm 38$ & $72 \pm 46$ & $55 \pm 29^{* * a} * * * \mathrm{~b}$ \\
\hline Insulin sens. $(\text { index })^{3}$ & $6.9 \pm 3.1$ & $7.0 \pm 3.8$ & $7.1 \pm 4.1$ & $9.4 \pm 5.2 * * \mathrm{a} * * * \mathrm{~b}$ \\
\hline BG AUC (mg/dL) & $597 \pm 113$ & $576 \pm 116$ & $604 \pm 100$ & $555 \pm 88^{* * * b}$ \\
\hline BG peak (mg/dL) & $131 \pm 23$ & $127 \pm 28$ & $135 \pm 28$ & $126 \pm 26 * * * a * * b$ \\
\hline Energy intake (Cal/d) & $1855 \pm 579$ & $1649 \pm 599$ & $1756 \pm 652$ & $1271 \pm 517^{* * * a} * * * \mathrm{~b}$ \\
\hline Meals per day ${ }^{4}$ & $3.9 \pm 0.7$ & $3.9 \pm 0.7$ & $3.9 \pm 0.6$ & $3.7 \pm 0.6^{* * b}$ \\
\hline Vegetable intake (g/d) & $199 \pm 209$ & $227 \pm 218$ & $313 \pm 242$ & $424 \pm 239^{* * * b}$ \\
\hline Fruit intake $(\mathrm{g} / \mathrm{d})$ & $183 \pm 148$ & $163 \pm 153$ & $221 \pm 150$ & $307 \pm 259^{* a} * * b$ \\
\hline
\end{tabular}

${ }^{1}$ Diary SD refers to BG SD of 21 measurements reported by each of $7 \mathrm{~d}$ diary.

${ }^{2}$ AUC: area under GTT curve.

${ }^{3}$ Whole body insulin sensitivity index [25].

${ }^{4}$ Meal was an event of higher energy intake than $20 \mathrm{kcal}$.

Values are expressed as mean \pm SD. Peak values include different observations from those at 30' during GTT. Asterisks indicate significance (Student's $t$-test:

$\left.{ }^{*} P<.05 ;{ }^{* *} P<.01 ;{ }^{* *} P<.001\right)$ of longitudinal difference versus respective control group (a) or versus baseline values of the same group (b).

AUC $(P=.001)$. Analysis of weight confirmed the BMI findings.

3.4. Adverse Events. Trained subjects reported few negative effects when adjusting their food intake and in accommodating irregular intermeal intervals in the first few days of trial and error. The reported adverse effects included a slightly depressed BG (below $60 \mathrm{mg} / \mathrm{dL}(3.3 \mathrm{mmol} / \mathrm{l})$ ) and weakness or abdominal pain.

\section{Discussion}

4.1. Limitations of the Study. The high number of dropouts is an important limitation of this study. However, from our sensitivity analysis, we conclude that the dropout subjects are unlikely to represent a significantly different population with respect to the endpoint measures of this study and that the absence of final data from these subjects is unlikely to have significantly affected the overall results.

4.2. Generalisability. Our findings are from subjects who attended a gastroenterology clinic over a 5-month period. Further investigation will be necessary to evaluate the effect of the IHMP in other populations and what "reminder" training might be necessary to ensure compliance with the IHMP over years.

\subsection{Interpretation}

4.3.1. Synopsis of Key Findings. A seven-week training program to establish the IHMP led to significant decreases in insulin sensitivity index, insulin and BG peaks, glycated haemoglobin, mean pre-meal BG and BG diary SD. Energy intake, BMI, and body weight also significantly decreased. 
4.3.2. Possible Mechanisms and Explanations. IH may represent an important afferent arm of a physiological regulation mechanism that provides meal-by-meal feedback on energy need thus optimizing energy intake. The observed improved insulin sensitivity may reflect lowered energy intake resulting from the IHMP.

4.3.3. Comparison with Previous Findings. Before training, mean pre-meal BG showed high intersubject variability, in agreement with other authors' findings. This variability has engendered a perception that BG has no relevance to food intake regulation [8]. The mean pre-meal BG in trained subjects decreased significantly over 5 months, whereas control subjects showed no change. We suggest, therefore, that inter-subject variability arises because in many subjects hunger (and thus LBG) is, by habit, forestalled by premature food intake leading to sustained mild hyperglycemia. That the absolute pre/post change (increase or decrease) in premeal BG was modest in 31 control subjects $(13.2 \% \pm 10.1 \%$ of baseline range in mean BG variation of 120 investigated subjects) supports the contention that in untrained subjects eating occurs according to long-standing habit.

4.3.4. Clinical and Research Implications. We suggest the IHMP offers a viable alternative to low fat and low carbohydrate diets [32] that is safe, cost-effective, and likely to be met with greater acceptance since it does not involve energy deprivation.

The ramifications of improved insulin sensitivity extend well beyond glucose homoeostasis [33-36]. For example, the chronic subclinical inflammation indicated by $\mathrm{C}$ reactive protein (CRP) is now seen as part of the insulin resistance syndrome $[33,35]$. Our results could thus have implications in a variety of inflammatory conditions. Trained subjects showed a cumulative energy balance that was negative after 5 months, and the longitudinal difference was significant in comparison with control subjects. Elsewhere, we describe the effect of the IHMP on body weight in relation to baseline weight and mean BG, using a larger sample size [23].

\section{Conclusions}

Our data suggest that (i) IH provides meal-by-meal feedback allowing the conscious formation of a new eating pattern (IHMP) and sustained self-regulation of energy intake, and (ii) over a five-month period the IHMP is associated with improvement in insulin sensitivity, LBG, HbAlc, and other cardiovascular risk factors.

These findings, together with those of an associated study on weight [23], suggest that the current epidemic of insulin resistance and overweight may have its origin in noncognizance of hunger. This may owe to habitual forestalling of hunger in early life and subsequent reinforcement of this behaviour pattern. By restoring and validating hunger, the IHMP could help in the prevention and treatment of diabetes and obesity and associated disorders. This could lessen the high economic burden of health services in industrialised societies.

\section{List of Abbreviations}

IHMP: Initial hunger meal pattern

AUC: $\quad$ Area under curve

BMI: $\quad$ Body mass index

BG: Blood glucose concentration

GTT: Oral glucose tolerance test

LBG: $\quad$ Low blood glucose

Diary-BG SD: Mean pre-meal blood glucose standard

CRP: $\quad$ C reactive protein.

\section{Acknowledgments}

The authors thank Laura Chiesi and Stefania Bini MD for dietary analyses and Stephen Buetow, Tim Kenealy, Chris Harshaw, Simon Thornton, Kent Berridge, James Gibbs, Charlotte Erlanson-Albertsson, and Michael Hermanussen for helpful insights on earlier drafts of this paper. This research was supported by the Italian Ministry of University, Research, Science and Technology grants for the years 19982002 and ONLUS Nutrizione e Prevenzione, Firenze for years 2003-2008. The authors declare that they have no competing interests.

\section{References}

[1] Institute of Medicine, Dietary Reference Intakes for Energy, Carbohydrate, Fiber, Fat, Fattyacids, Cholesterol, Protein, and Aminoacids, US and Canada, 2002.

[2] R. Weiss, J. Dziura, T. S. Burgert, W. V. Tamborlane, S. E. Taksali, C. W. Yeckel, K. Allen, M. Lopes, M. Savoye, J. Morrison, R. S. Sherwin, and S. Caprio, "Obesity and the metabolic syndrome in children and adolescents," New England Journal of Medicine, vol. 350, no. 23, pp. 2362-2374, 2004.

[3] A. J. Hill, L. D. Magson, and J. E. Blundell, "Hunger and palatability: tracking ratings of subjective experience before, during and after the consumption of preferred and less preferred food," Appetite, vol. 5, no. 4, pp. 361-371, 1984.

[4] K. Trottier, J. Polivy, and C. P. Herman, "Effects of exposure to unrealistic promises about dieting: are unrealistic expectations about dieting inspirational?" International Journal of Eating Disorders, vol. 37, no. 2, pp. 142-149, 2005.

[5] M. R. Lowe, "Self-regulation of energy intake in the prevention and treatment of obesity: is it feasible?" Obesity Research, vol. 11, no. 1, pp. 44S-59S, 2003.

[6] C. De Graaf, W. A. M. Blom, P. A. M. Smeets, A. Stafleu, and H. F. J. Hendriks, "Biomarkers of satiation and satiety," American Journal of Clinical Nutrition, vol. 79, no. 6, pp. 946-961, 2004.

[7] J. R. Gavin III, "Pathophysiologic mechanisms of postprandial hyperglycemia," American Journal of Cardiology, vol. 88, no. 2, pp. S4-S8, 2001.

[8] S. S. Elliott, N. L. Keim, J. S. Stern, K. Teff, and P. J. Havel, "Fructose, weight gain, and the insulin resistance syndrome," American Journal of Clinical Nutrition, vol. 76, no. 5, pp. 911922, 2002.

[9] T. J. Merimee and J. E. Tyson, "Stabilization of plasma glucose during fasting. Normal variations in two separate studies," New England Journal of Medicine, vol. 291, no. 24, pp. 12751278, 1974. 
[10] L. A. Campfield and F. J. Smith, "Functional coupling between transient declines in blood glucose and feeding behavior: temporal relationships," Brain Research Bulletin, vol. 17, no. 3, pp. 427-433, 1986.

[11] M. Ciampolini, A. Conti, S. Bernardini, et al., "Internal stimuli controlled lower calorie intake: effects after eight months in toddler's diarrhoea," Italian Journal of Gastroenterology, vol. 19, pp. 201-204, 1987.

[12] M. Ciampolini, D. Vicarelli, and S. Seminara, "Normal energy intake range in children with chronic nonspecific diarrhea: association of relapses with the higher level," Journal of Pediatric Gastroenterology and Nutrition, vol. 11, no. 3, pp. 342-350, 1990.

[13] M. Ciampolini, D. Vicarelli, and S. Bini, "Choices at weaning: main factor in ingestive behavior," Nutrition, vol. 7, no. 1, pp. 51-54, 1991.

[14] M. Ciampolini, P. Becherucci, A. Giommi, D. Vicarelli, S. Seminara, S. Bini, and G. Grifi, "Decrease in serum IgE associated with limited restriction in energy intake to treat toddler's diarrhea," Physiology and Behavior, vol. 49, no. 1, pp. 155-160, 1991.

[15] S. Bini, M. Ciampolini, L. Chiesi, and D. Vicarelli, "Energyneed and glycemia before the meals of 23 normal-weight IBS adults," Appetite, vol. 19, p. 166, 1992.

[16] M. Ciampolini and R. Bianchi, "Training to estimate blood glucose and to form associations with initial hunger," Nutrition and Metabolism, vol. 3, article 42, 2006.

[17] D. Chapelot, C. Marmonier, R. Aubert, N. Gausseres, and J. Louis-Sylvestre, "A role for glucose and insulin preprandial profiles to differentiate meals and snacks," Physiology and Behavior, vol. 80, no. 5, pp. 721-731, 2004.

[18] N. J. Talley, "Dyspepsia," Gastroenterology, vol. 125, no. 4, pp. 1219-1226, 2003.

[19] D. A. Drossman, "The functional gastrointestinal disorders and the Rome III process," Gastroenterology, vol. 130, no. 5, pp. 1377-1390, 2006.

[20] M. Ciampolini, S. Bini, A. Giommi, D. Vicarelli, and V. Giannellini, "Same growth and different energy intake over four years in children suffering from chronic non-specific diarrhoea," International Journal of Obesity, vol. 18, no. 1, pp. 17-23, 1994.

[21] M. Ciampolini, L. Borselli, and V. Giannellini, "Attention to metabolic hunger and its effects on Helicobacter pylori infection," Physiology and Behavior, vol. 70, no. 3-4, pp. 287296, 2000.

[22] M. Ciampolini, "Infants do request food at the hunger blood glucose level, but adults don't any more (Abstract)," Appetite, vol. 46, p. 345, 2006.

[23] M. Ciampolini, D. Lovell-Smith, and M. Sifone, "Sustained self-regulation of energy intake. Loss of weight in overweight subjects. Maintenance of weight in normal-weight subjects," Nutrition and Metabolism, vol. 7, article 4, 2010.

[24] K. Morihara, T. Oka, H. Tsuzuki, Y. Tochino, and T. Kanaya, "Achromobacter protease I-catalyzed conversion of porcine insulin into human insulin," Biochemical and Biophysical Research Communications, vol. 92, no. 2, pp. 396-402, 1980.

[25] M. Matsuda and R. A. DeFronzo, "Insulin sensitivity indices obtained from oral glucose tolerance testing: comparison with the euglycemic insulin clamp," Diabetes Care, vol. 22, no. 9, pp. 1462-1470, 1999.

[26] P. Wiesli, E. Schäffler, B. Seifert, C. Schmid, and M. Y. Donath, "Islet secretory capacity determines glucose homoeostasis in the face of insulin resistance," Swiss Medical Weekly, vol. 134, no. 37-38, pp. 559-564, 2004.

[27] D. E. Singer, D. M. Nathan, K. M. Anderson, P. W. F. Wilson, and J. C. Evans, "Association of $\mathrm{HbA}(1 \mathrm{c})$ with prevalent cardiovascular disease in the original cohort of the Framingham Heart Study," Diabetes, vol. 41, no. 2, pp. 202-208, 1992.

[28] P. Armitage and G. Berry, Statistical Methods in Medical Research, Blackwell, Oxford, UK, 3rd edition, 1994.

[29] K. Godfrey, "Comparing the means of several groups," New England Journal of Medicine, vol. 313, no. 23, pp. 1450-1456, 1985.

[30] V. M. Montori and G. H. Guyatt, "Intention-to-treat principle," Canadian Medical Association Journal, vol. 165, no. 10, pp. 1339-1341, 2001.

[31] R. D. Feinman, "Intention-to-treat. What is the question?" Nutrition and Metabolism, vol. 6, article 1, 2009.

[32] B. J. Brehm and D. A. D'Alessio, "Benefits of high-protein weight loss diets: enough evidence for practice?" Current Opinion in Endocrinology, Diabetes and Obesity, vol. 15, no. 5, pp. 416-421, 2008.

[33] G. M. Reaven, "The metabolic syndrome: is this diagnosis necessary?" American Journal of Clinical Nutrition, vol. 83, no. 6, pp. 1237-1247, 2006.

[34] S. B. Biddinger and C. R. Kahn, "From mice to men: insights into the insulin resistance syndromes," Annual Review of Physiology, vol. 68, pp. 123-158, 2006.

[35] A. Festa, R. D’Agostino Jr., G. Howard, L. Mykkänen, R. P. Tracy, and S. M. Haffner, "Chronic subclinical inflammation as part of the insulin resistance syndrome: the Insulin Resistance Atherosclerosis Study (IRAS)," Circulation, vol. 102, no. 1, pp. 42-47, 2000.

[36] D. E. Moller and J. S. Flier, "Insulin resistance-mechanisms, syndromes, and implications," New England Journal of Medicine, vol. 325, no. 13, pp. 938-948, 1991. 


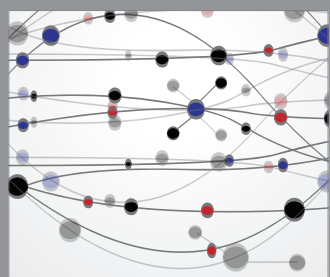

The Scientific World Journal
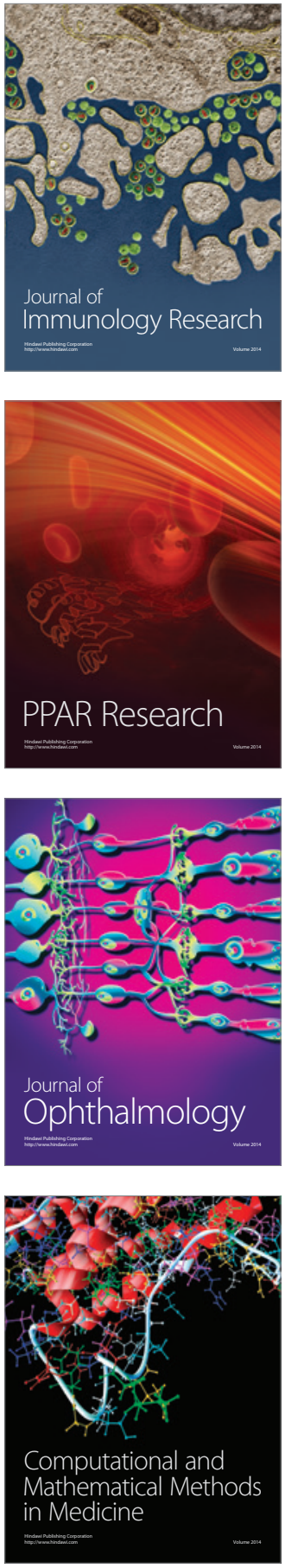

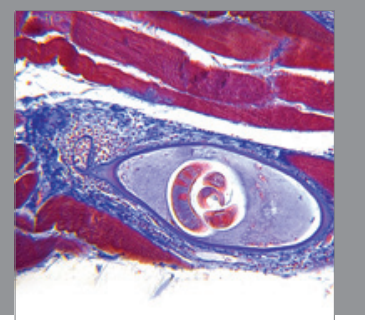

Gastroenterology

Research and Practice
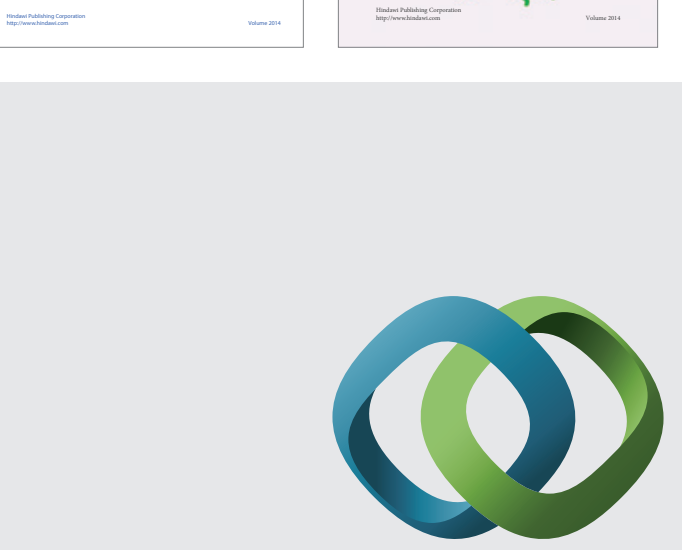

\section{Hindawi}

Submit your manuscripts at

http://www.hindawi.com
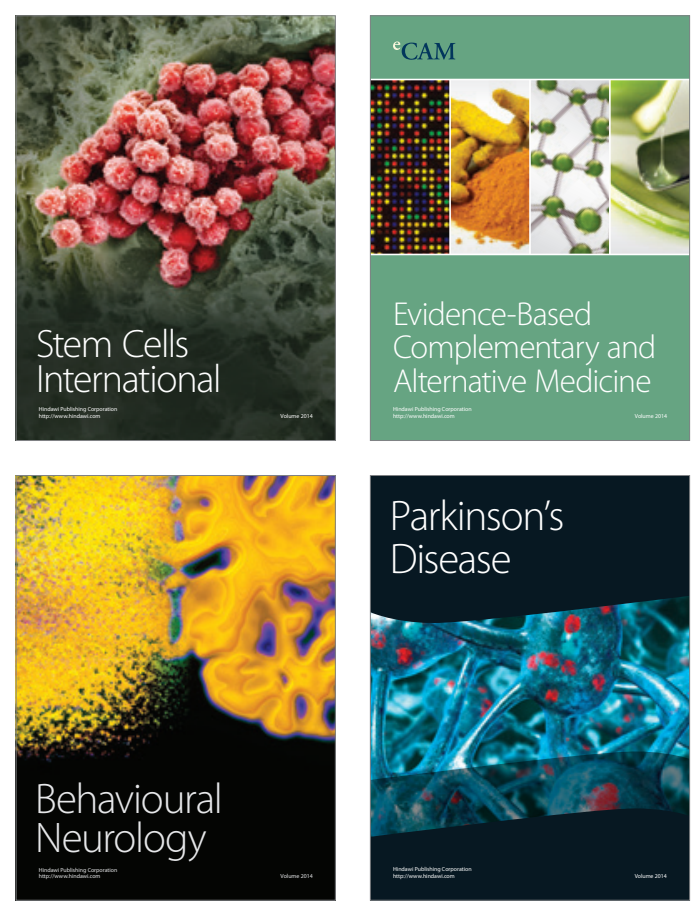

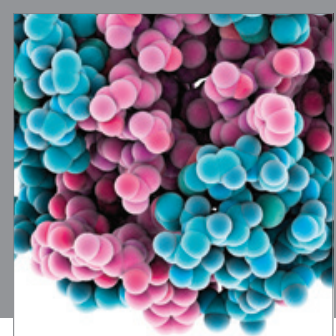

Journal of
Diabetes Research

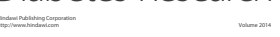

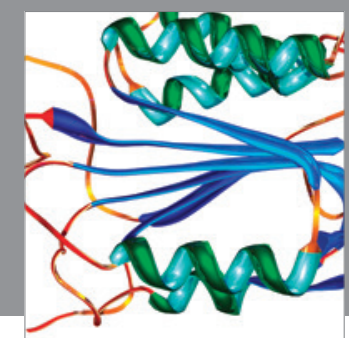

Disease Markers
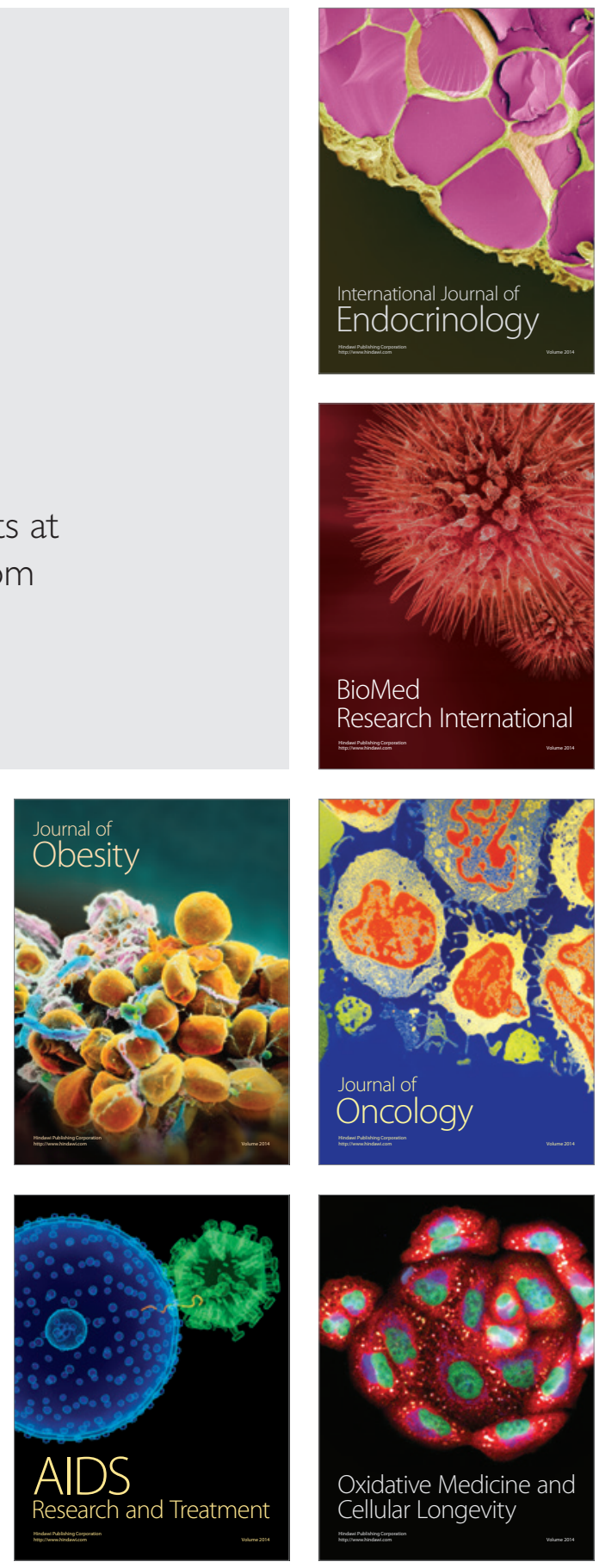